\title{
Eventos relacionados con docencia universitaria
}

VIII Congreso Iberoamericano de Docencia Universitaria y de Nivel Superior "La construcción de saberes acerca de la enseñanza: un desafío para la docencia universitaria y de nivel superior"

21, 22 y 23 de abril de 2014 .

Facultad de Humanidades y Artes de la Universidad Nacional de Rosario (Argentina).

Más información en: www.iberoamericano2014.unr.edu.ar

Jornadas RED-U “Repensar la Formación del Profesorado hoy”

27 y 28 de noviembre de 2013.

Instituto Ciencias Educación, Universidad Politécnica de Valencia (España).

Más información en: http://www.red-u.org/

VII Encuentro Nacional y IV Latinoamericano: "La Universidad Como Objeto De Investigación ». Universidad y democracia en Argentina y América Latina.

29, 30 y 31 de Agosto del 2013.

Universidad Nacional de San Luis (Argentina).

Más información en: encuentro7@unsl.edu.ar

Simposio internacional sobre "Aprender a ser docente en un mundo en cambio"

21 y 22 de noviembre de 2013.

Barcelona (España)

Más información en: http://som.esbrina.eu/aprender/ 